OPEN ACCESS

Edited by:

Lisa Topolnik,

Laval University, Canada

Reviewed by:

Costas E. Papatheodoropoulos,

University of Patras, Greece

Emmanuel Valjent,

Centre National de la Recherche

Scientifique (CNRS), France

*Correspondence:

Denise Manahan-Vaughan denise.manahan-vaughan@rub.de

Received: 15 August 2019 Accepted: 24 September 2019

Published: 15 October 2019

Citation:

Dubovyk $V$ and Manahan-Vaughan D (2019) Gradient of Expression of Dopamine D2 Receptors Along the Dorso-Ventral Axis of the Hippocampus. Front. Synaptic Neurosci. 11:28. doi: 10.3389/fnsyn.2019.00028

\section{Gradient of Expression of Dopamine D2 Receptors Along the Dorso-Ventral Axis of the Hippocampus}

\author{
Valentyna Dubovyk ${ }^{1,2}$ and Denise Manahan-Vaughan ${ }^{1 *}$ \\ ${ }^{1}$ Medical Faculty, Department of Neurophysiology, Ruhr University Bochum, Bochum, Germany, ${ }^{2}$ International Graduate \\ School of Neuroscience, Ruhr University Bochum, Bochum, Germany
}

Dopamine D2-like receptors (D2R) play an important role in the regulation of hippocampal neuronal excitability and contribute to the regulation of synaptic plasticity, the encoding of hippocampus-dependent memories and the regulation of affective state. In line with this, D2R are targeted in the treatment of psychosis and affective disorders. It has been proposed that the dorso-ventral axis of the hippocampus can be functionally delineated into the dorsal pole that predominantly processes spatial information and the ventral pole that mainly addresses hippocampal processing of emotional and affective state. Although dopaminergic control of hippocampal information processing has been the focus of a multitude of studies, very little is known about the precise distribution of D2R both within anatomically defined sublayers of the hippocampus and along its dorsoventral axis, that could in turn yield insights as to the functional significance of this receptor in supporting hippocampal processing of spatial and affective information. Here, we used an immunohistochemical approach to precisely scrutinize the protein expression of D2R both within the cellular and dendritic layers of the hippocampal subfields, and along the dorso-ventral hippocampal axis. In general, we detected significantly higher levels of protein expression of D2R in the ventral, compared to the dorsal poles with regard to the CA1, CA2, CA3 and dentate gyrus (DG) regions. Effects were very consistent: the molecular layer, granule cell layer and polymorphic layer of the DG exhibited higher D2R levels in the ventral compared to dorsal hippocampus. D2R levels were also significantly higher in the ventral Stratum oriens, Stratum radiatum, and Stratum lacunosum-moleculare layers of the CA1 and CA3 regions. The apical dendrites of the ventral CA2 region also exhibited higher D2R expression compared to the dorsal pole. Taken together, our study suggests that the higher D2R expression levels of the ventral hippocampus may contribute to reported gradients in the degree of expression of synaptic plasticity along the dorso-ventral hippocampal axis, and may support behavioral information processing by the ventral hippocampus.

Keywords: dopamine receptor, hippocampus, immunohistochemistry, rodent, dorso-ventral axis 


\section{INTRODUCTION}

Synaptic plasticity and memory formation in the hippocampus, in their essence, are dependent on excitatory glutamatergic transmission (Citri and Malenka, 2008; Lisman, 2017). However, various neurotransmitter systems exert a modulatory role, thereby influencing the direction of change (Kemp and Manahan-Vaughan, 2005), effectiveness (Hansen and ManahanVaughan, 2015), duration (Twarkowski and Manahan-Vaughan, 2016) or robustness (Manahan-Vaughan and Kulla, 2003) of synaptic strength, and learning and memory. The dopaminergic system is one such modulatory influence on neuronal and synaptic activity (Kulla and Manahan-Vaughan, 2000; Lemon and Manahan-Vaughan, 2012; Hansen and Manahan-Vaughan, 2014; Madadi Asl et al., 2019).

Dopamine exerts its action by means of slow modulation of fast neurotransmission through its G-protein-coupled receptors. Five types of dopaminergic receptors have been identified that are subdivided into D1 (D1 and D5) and D2 (D2, D3 and D4) classes of receptors based on their ability to modulate cAMP production and their structural, biochemical and pharmacological properties (Sibley and Monsma, 1992; Vallone et al., 2000; Beaulieu and Gainetdinov, 2011). While the D1-class receptors stimulate adenylyl cyclase (AC) activity and therefore cAMP production, the D2-class receptors inhibit AC activity, thus hindering cAMP production. D2 receptors also modulate the beta-arrestin/GSK3 pathway and can alter the excitability of hippocampal mossy cells through this mechanism (Etter and Krezel, 2014). Both classes of dopamine receptors are postsynaptically expressed on dopamine-receptive cells (Rankin et al., 2009). Interestingly, only the D2-class receptors exist in different isoforms (Gingrich and Caron, 1993). The D2 dopamine receptor (D2R) exists in D2S (short) and D2L (long) variants. Whereas D2S is predominantly expressed presynaptically, D2L is mostly postsynaptically expressed (Usiello et al., 2000; De Mei et al., 2009). Thus, the D2R enables a more complex modulation of neuronal circuitry than that exerted by other dopamine receptor types. Moreover, the $\mathrm{D} 2 \mathrm{R}$ is the only dopamine receptor that has been directly implicated in several brain conditions, such as drug addiction, Parkinson's disease and schizophrenia (Wong et al., 1986; Volkow et al., 2007; Chaudhuri and Schapira, 2009). Therefore, in-depth knowledge about the spatial expression pattern of D2R would be beneficial for understanding not only the physiological role, but also, the pathological role of this receptor.

Surprisingly, despite the wealth of studies on the dopaminergic system, very little is known about D2R expression in the hippocampus proper (Gasbarri et al., 1997; Beaulieu and Gainetdinov, 2011); most studies to date, focused on the basal ganglia and occasionally on the frontal cortex (Levey et al., 1993; Yung et al., 1995; Santana et al., 2009; Lavian et al., 2018). The most extensive examination of D2R expression in rat hippocampus up to now was performed by Yu et al. (2019). In their work they showed that D2R is mainly expressed in cells of the Stratum pyramidale ( $\mathrm{sp}$ ) and Stratum radiatum (sr) layers of the CA1-3 regions, in the dentate gyrus (DG), and in axon terminals innervating the Stratum lacunosummoleculare (slm) of the CA1 of the dorsal hippocampus. Despite their extensive investigation, the authors omitted scrutiny of the overall expression level of D2R across the layers of the trisynaptic circuit of the hippocampus, as well as across its dorso-ventral axis.

The hippocampal dorso-ventral axis is functionally segregated into the dorsal part that is essential for visuo-spatial information processing, the ventral part that is involved in emotional, motivational and affective responses, and the intermediate part that integrates information from both poles (Bast et al., 2009; Fanselow and Dong, 2010; Strange et al., 2014). Hippocampal dopamine originates from neurons of the ventral tegmental area (VTA) and locus coeruleus (LC; Lisman and Otmakhova, 2001; Lemon et al., 2009; Smith and Greene, 2012) . Projections from the LC predominantly terminate in the dorsal hippocampus (Kempadoo et al., 2016), whereas projections from the VTA are the strongest in the ventro-intermediate hippocampal two-thirds (Gasbarri et al., 1994). This segregation in innervation by dopamine-containing terminals (Duszkiewicz et al., 2019) further suggests that dopaminergic transmission may exert a non-uniform influence across the hippocampal longitudinal axis. This may be mediated by the degree of dopamine release, but also by differences in receptor expression. Here, the D2R is of particular interest: it is intrinsically involved in the regulation of hippocampal basal synaptic transmission and of the robustness of synaptic plasticity (Manahan-Vaughan and Kulla, 2003).

In this work, we used an immunohistochemical approach to conduct a detailed study of the expression and distribution pattern of D2R across the layers of the DG and cornu ammonis (CA) regions of the dorsal, intermediate and ventral hippocampus of the rat. We observed differences in the expression gradient of this receptor along the dorso-ventral hippocampal axis, and within the microcircuitry of the hippocampus. Our data provide new insights into hippocampal D2R expression that may help in understanding the cellular mechanisms behind D2R modulation of neuronal excitability and synaptic plasticity in the hippocampus.

\section{MATERIALS AND METHODS}

\section{Animals}

All experiments were conducted using 8-12-week-old male Wistar rats (Charles River Laboratories, Sulzfeld, Germany). Animals were housed in custom-made climatized and ventilated holding cupboards in an animal-housing room with a controlled 12-h light/dark cycle. No female rats were housed in the room. Water and food were available ad libitum. The study was carried out in accordance with the European Communities Council Directive of September 22nd, 2010 (2010/63/EU) for care of laboratory animals and all experiments were conducted according to the guidelines of the German Animal Protection Law. They were approved in advance by the North Rhine-Westphalia (NRW) State Authority (Landesamt für Arbeitsschutz, Naturschutz, Umweltschutz und Verbraucherschutz, NRW). All efforts were made to reduce the number of animals used. 


\section{Slice Preparation}

Wistar rats were deeply anesthetized with sodium pentobarbital and transcardially perfused with cold Ringer's solution + heparin $(0.2 \%)$ followed by $4 \%$ paraformaldehyde (PFA) in phosphate buffered saline (PBS, $0.025 \mathrm{M}$ ). Brains were removed, fixed in $4 \%$ PFA for $24 \mathrm{~h}$, and cryoprotected in 30\% sucrose in $0.1 \mathrm{M}$ PBS for at least 3 days. Serial $30-\mu \mathrm{m}$ thick horizontal sections were collected with a freezing microtome. For each animal $(N=10)$, three horizontal sections from the most dorsal (between 3.6 and $4.1 \mathrm{~mm}$ posterior to Bregma), middle intermediate (around $5.6 \mathrm{~mm}$ posterior to Bregma) and most ventral hippocampal parts (between 7.1 and $7.6 \mathrm{~mm}$ posterior to Bregma) were simultaneously used for immunohistochemical staining (Figure 2).

\section{Verification of Antibody Specificity}

The specificity of the D2R antibody was conducted using western blotting (Figure 1). Following brain removal, the hippocampus was rapidly isolated and then homogenized in $20 \mathrm{mM}$ Tris- $\mathrm{HCl}$ buffer ( $\mathrm{pH}$ 7.4) containing 10\% sucrose, followed by centrifugation at $14,000 \mathrm{rpm}$ for $30 \mathrm{~min}$ at $4^{\circ} \mathrm{C}$ in $20 \mathrm{mM}$ Tris- $\mathrm{HCl}$ buffer supplemented with protease inhibitor. The supernatant was removed and the pellet was resuspended in $20 \mathrm{mM}$ Tris- $\mathrm{HCl}$ buffer supplemented with protease inhibitor. The protein concentration of the samples was determined with a Bradford assay. Protein samples were separated in $8 \%$ SDS polyacrylamide gels that were prepared 1 day before use. Prior to gel electrophoresis, the required amount of sample (minimum $10 \mu \mathrm{g}$ of protein per sample) was mixed with the same amount of twice-concentrated $(2 \times)$ Laemmli buffer. Samples were then heated for $5 \mathrm{~min}$ at $100^{\circ} \mathrm{C}$, briefly centrifuged and loaded on to gels. The first line on the gel was always filled with protein marker in the amount of $5 \mu \mathrm{g}$, which was then separated into fragments of distinct molecular weights. Gel-electrophoresis was performed for $\sim 1.5 \mathrm{~h}$ at $400 \mathrm{~V}$ and $15 \mathrm{~mA}$ settings per gel. Afterward, gels were removed from the running chamber and left in the cold transfer buffer, while the polyvinyl difluoride membranes (PVDF) were incubated with methanol for approx. 5 min. Membranes were then briefly washed with distilled water and covered with transfer buffer. After the transfer "sandwiches" were assembled, they were placed into the transfer chamber, covered with cold transfer buffer and the wet-transfer of proteins from gel onto membranes began $(400 \mathrm{~V}, 300 \mathrm{~mA}, 1.5 \mathrm{~h})$.

Membranes were then blocked for $1 \mathrm{~h}$ [5\% non-fat dry milk, $0.1 \%$ Tween 20 in tris-buffered saline (TBS)] at room temperature. Blots were then incubated overnight at $4^{\circ} \mathrm{C}$ with the primary $\mathrm{D} 2 \mathrm{R}$ antibody that was used for immunohistochemistry: rabbit polyclonal anti-D2R (ab-1558, Millipore) at 1:1,000 dilution. The primary antibody was dissolved in boost signal solution (Calbiochem). Membranes were then washed 3 times in $0.1 \%$ Tween 20 in TBS and incubated with secondary antibody dissolved in boost signal solution (Calbiochem). Protein bands were visualized using an enhanced chemiluminescence reagent. A distinct band was found at ca. $55 \mathrm{kDa}$ (Figure 1) consistent with specific labeliing of the D2L receptor that is postsynaptically localized, by the antibody used here (Gemechu et al., 2018).

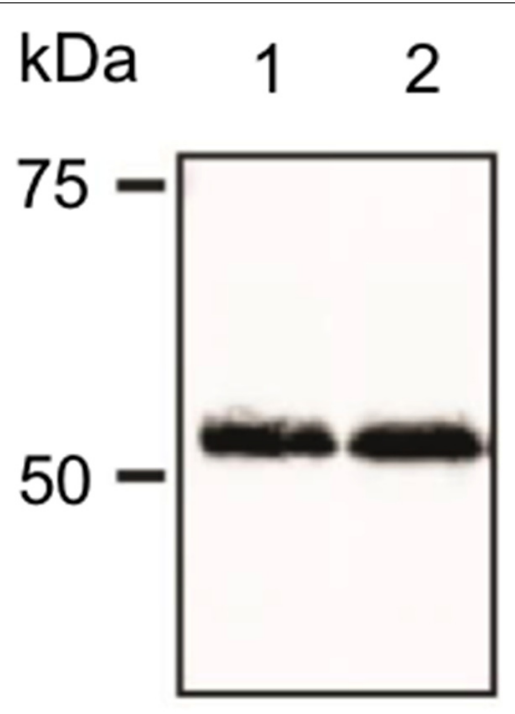

FIGURE 1 | Verification of antibody specificity. Example of a western blot showing binding specificity of the dopamine D2-like receptor (D2R) antibody used in the immunohistochemistry experiments. The antibody labeled a band of ca. $55 \mathrm{kDa}$, corresponding to the reported $\mathrm{kDa}$ weight of the target receptor as reported by others (Gemechu et al., 2018).

\section{Immunohistochemistry}

Endogenous peroxidase was blocked by pretreating the free-floating brain sections in $0.3 \% \mathrm{H}_{2} \mathrm{O}_{2}$ for $20 \mathrm{~min}$. They were then rinsed in PBS and incubated with blocking solution containing $10 \%$ normal serum and $20 \%$ avidin in PBS with $0.2 \%$ Triton X-100 (PBS-Tx) for $90 \mathrm{~min}$ at room temperature. Sections were incubated overnight at room temperature with primary D2R antibodies (rabbit polyclonal, 1:250; ab-1558, Millipore) in medium containing $1 \%$ normal serum in $0.2 \%$ PBS-Tx + $20 \%$ biotin. Sections were then rinsed in PBS and incubated with biotinylated goat anti-rabbit (1:500; BA-1,000, Vector) antibodies in $1 \%$ normal serum in $0.1 \%$ PBS-Tx for $90 \mathrm{~min}$ at RT. Afterward, sections were washed in PBS and incubated for 90 min at RT with ABC kit (PK-6,100, Vector) in 1\% normal serum in $0.1 \%$ PBS-Tx. Finally, sections were washed in PBS and treated with diaminobenzidine (DAB) and $0.01 \% \mathrm{H}_{2} \mathrm{O}_{2}$ for approx. $10 \mathrm{~min}$.

\section{Quantitative Analysis}

Regions of interest were defined using the rat brain atlas of Paxinos and Watson (1982) and Nissl staining where every 12th section throughout the whole hippocampus was stained with $0.1 \%$ Cresylviolet (c5042, Sigma) as a reference. Fifteen areas of interest included: the molecular layer $(\mathrm{ml})$ of the DG; the granule cell layer $(\mathrm{gcl})$ of the DG; the polymorphic layer (pl) of the DG; the Stratum oriens (so) of CA3/CA2/CA1; the pyramidal cell layer $(\mathrm{pcl})$ of $\mathrm{CA} 3 / \mathrm{CA} 2 / \mathrm{CA} 1$; the Stratum radiatum (sr) of CA3/CA2/CA1; and the Stratum lacunosummoleculare $(\mathrm{slm})$ of $\mathrm{CA} 3 / \mathrm{CA} 2 / \mathrm{CA} 1$ on sections taken from the dorsal, intermediate and ventral hippocampal subdivisions (Figure 2). Both, right and left hippocampi were used for the analysis and considered as replicates. For background 

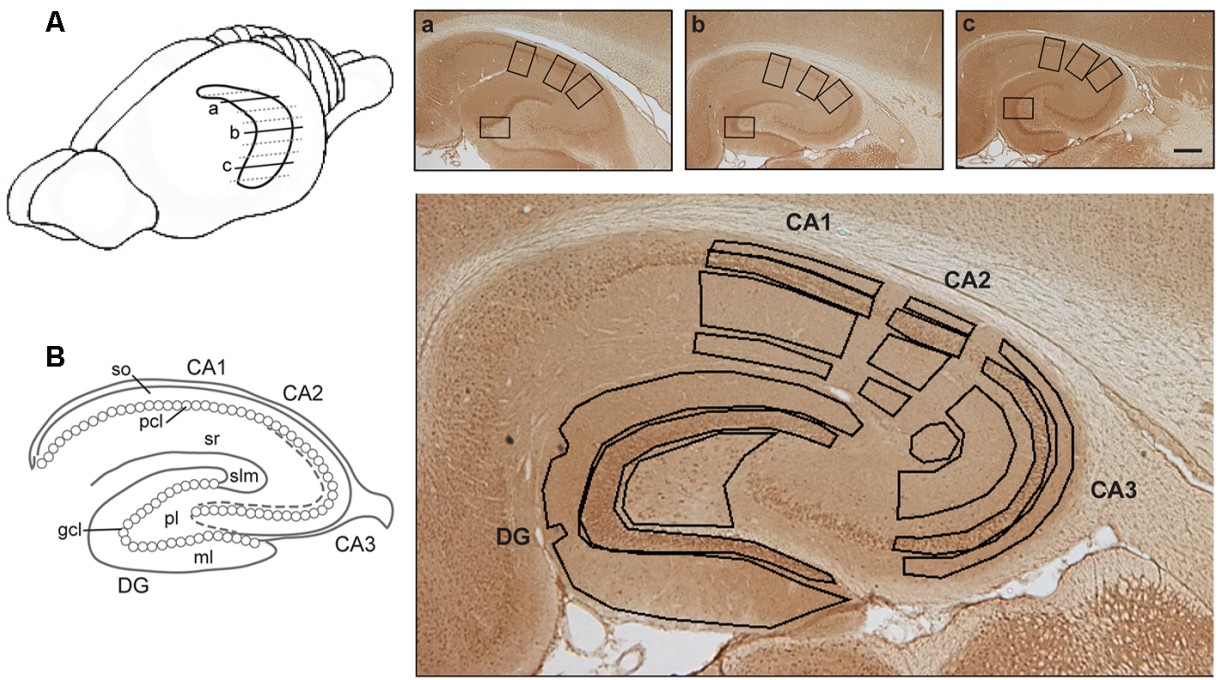

\section{C}
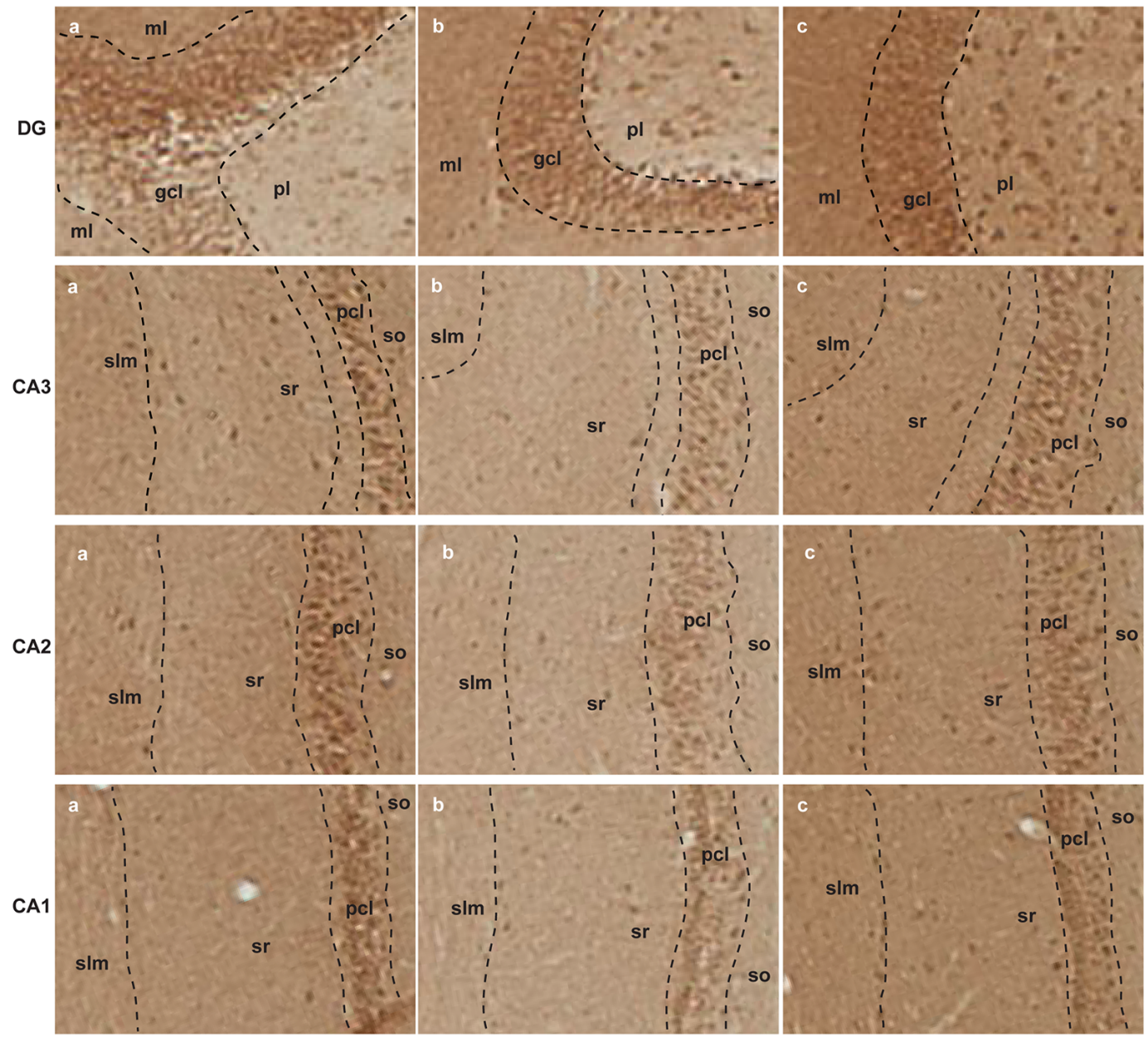

FIGURE 2 | Illustration of hippocampal separation into longitudinal and transverse axes. (A) A drawing of the rat brain with horizontally sectioned hippocampus is presented. Representative images of immunohistochemically stained sections against D2R of the dorsal (a), intermediate (b) and ventral hippocampus (c) from the same animal are shown. Scale bar is $500 \mu \mathrm{m}$. Squares on each image correspond to zoom-in fragments on the panel (C). (B) Schematic representation of the hippocampal transverse axis and laminar separation (left). Immunohistochemically stained section with marked regions taken for the analysis is depicted (right). Abbreviations correspond to: $\mathrm{ml}$, molecular layer of the DG; gcl, granule cell layer of the DG; pl, polymorphic layer of the DG; so, Stratum oriens of CA3/CA2/CA1; pcl, pyramidal cell layer of CA3/CA2/CA1; sr, Stratum radiatum of CA3/CA2/CA1; and slm, Stratum lacunosum-moleculare of CA3/CA2/CA1. (C) A closer view of subsections of the dentate gyrus (DG) and CA regions from the dorsal (a), intermediate (b) and ventral (c) hippocampal sections, including the laminar delineation, is shown. 


\section{DG region}
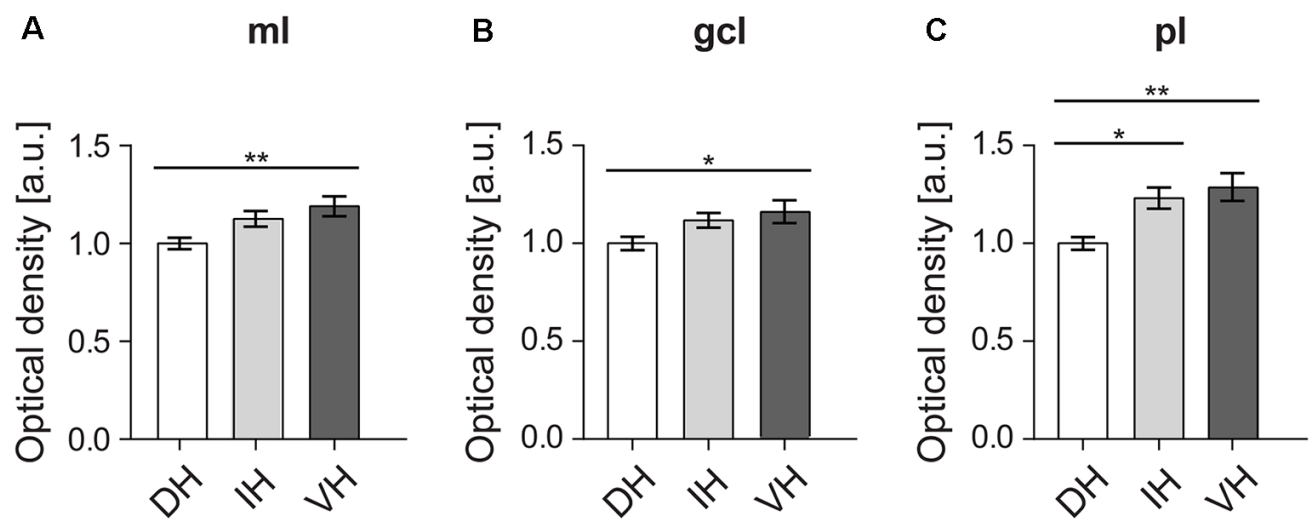

FIGURE 3 | In the DG, the dorsal component exhibits the lowest D2R expression. The molecular layer (ml) (A) and granule cell layer (gcl) of the ventral DG (B) exhibit higher D2R levels compared to the dorsal DG. The polymorphic layer (pl) (C) of the dorsal DG shows the lowest receptor expression as opposed to the ventro-intermediate DG. Values expressed in arbitrary units (a.u.). Error bars indicate standard error of the mean (SEM). * $p<0.05$ or $* * p<0.01$. ml, molecular layer; gcl, granule cell layer; pl, polymorphic layer.

subtraction, we used receptor-devoid tissue. In the dorsal sections this comprised the fimbria. In the intermediate sections, this comprised the superior thalamic radiation, and in the ventral sections, this was the internal capsule. Pictures of stained sections were acquired with a light microscope (Leica DMR, Germany), equipped with a digital camera (MBF Bioscience) and stored in TIFF format. The regions of interest were analyzed at $2.5 \times$ lens magnification. The digitized high-resolution pictures were obtained using Neurolucida software (MBF Bioscience) and quantified using open-source ImageJ software (National Institute of Health). Given that images were acquired with a RGB camera the "Color Deconvolution" plugin in ImageJ was used to deconvolve the color information as well as to convert images to 8-bit format, thus increasing the dynamic range of the signal. $\mathrm{R}$ software was used to scale data from several independent stainings/plates using generalized residual sum of squares algorithm to account for batch variability in staining intensities (Kreutz et al., 2007; von der Heyde et al., 2014).

\section{Statistical Analysis}

Receptor expression differences between hippocampal subfields for each layer of the trisynaptic circuit were statistically analyzed using a one-way analysis of variance (ANOVA) followed by Tukey HSD post hoc test. Here, statistical comparisons were made for a hippocampal layer of interest between the dorsal, intermediate and ventral subdivisions of 10 animals. In the subsequent text descriptions, " $M$ " corresponds to the mean, while "SD" refers to the standard deviation. All significant differences were defined as $p<0.05, p<0.01$ or $p<0.001$. Values are expressed as mean values \pm the standard error of the mean (SEM).

\section{RESULTS}

\section{In the Dentate Gyrus the Dorsal Component Exhibits the Lowest D2R Expression}

In order to better understand the functional differences across the hippocampal longitudinal axis, we examined the protein levels of $\mathrm{D} 2 \mathrm{R}$ in the $\mathrm{DG}, \mathrm{CA} 3, \mathrm{CA} 2$ and $\mathrm{CA} 1$ regions of the rat dorsal, intermediate and ventral hippocampus by immunohistochemical staining. Of all regions examined, the dorsal DG exhibited the lowest levels of D2R compared to expression levels in the ventral hippocampus. Effects were significant for the molecular layer, granule cell layer and the polymorphic layer (Figure 3).

A one-way ANOVA analysis revealed a significant effect for the three hippocampal parts in the molecular layer of the DG (Figure 3A; $F_{(2,57)}=5.665, p<0.01$ ). Post hoc Tukey HSD test revealed that the mean score for the dorsal part $(M=1, S D=0.12)$ was significantly lower from the ventral part $(M=1.19, S D=0.22)$. The intermediate part $(M=1.12$, $S D=0.17)$ did not differ from the other two hippocampal poles (Figure 3A).

Similarly, there was a significant effect in the granule cell layer of the DG (Figure 3B; $F_{(2,57)}=3.52, p<0.05$ ) analysis. Again, the post hoc test showed a difference in the mean score between the dorsal part $(M=1, S D=0.14)$ and the ventral one $(M=1.16$, $S D=0.26)$, while the intermediate part $(M=1.11, S D=0.16)$ was not different compared to the other two (Figure 3B).

In case of the polymorphic layer of the DG (Figure 3C), the dorsal part $(M=1, S D=0.14)$ displayed significantly lower D2R levels $\left(F_{(2,57)}=7.691, p<0.01\right)$ compared to both, the intermediate $(M=1.23, S D=0.24)$ and 
the ventral hippocampi $(M=1.28, S D=0.32)$. Receptor expression did not differ between the intermediate and ventral parts (Figure 3C).

\section{In the CA3 Region, the Ventral Component Shows the Highest D2R Expression}

Analysis of the D2R expression between the dorsal, intermediate and ventral hippocampal parts for the four layers of the CA3 region (Figure 4) revealed uniformly higher D2R levels in the ventral third, compared to the dorso-intermediate two-thirds.

Specifically, in the Stratum oriens of the CA3 statistically significant higher D2R expression was found in the ventral CA3 $\left(F_{(2,57)}=8.973, p<0.001\right)$. This was apparent between the ventral $(M=1.3, S D=0.28)$ vs. the dorsal part $(M=1, S D=0.19)$, and the ventral vs. the intermediate part $(M=1.1, S D=0.21$; Figure 4A). In the pyramidal cell layer of the CA3, the ventral part $(M=1.21, S D=0.2)$ also showed significantly higher D2R expression $\left(F_{(2,57)}=9.386, p<0.001\right)$ compared to the dorsal layer $(M=1, S D=0.12)$, as well as compared to the intermediate layer $(M=1.08, S D=1.44$; Figure 4B).

Furthermore, D2R expression was higher in the Stratum radiatum of the ventral CA3 region: the dorsal $(M=1, S D=0.21)$ and intermediate $(M=1.14, S D=0.19)$ parts express significantly less D2R $\left(F_{(2,57)}=14.05, p<0.001\right)$ compared to the ventral hippocampus $(M=1.39, S D=0.29$; Figure $4 C)$. In addition, the Stratum lacunosum-moleculare of the CA3 region followed the same pattern with $\mathrm{D} 2 \mathrm{R}$ expression being higher in the ventral component $\left(F_{(2,57)}=8.499, p<0.001\right.$; ventral portion: $M=1.28$, $S D=0.26$; dorsal: $M=1, S D=0.18$; and intermediate: $M=1.09$, $S D=0.2$; Figure 4D).

\section{In the CA2 Region, D2R Expression Is Highest in the Ventral Apical Dendrites}

Statistical analysis did not reveal any differences between the dorsal $(M=1, S D=0.14)$, intermediate $(M=1, S D=0.19)$ and ventral parts $(M=1.12, S D=0.19)$ of the Stratum oriens of the CA2 region $\left(F_{(2,57)}=3.324, p<0.05\right.$; Figure 5A). Likewise, no differences were found $\left(F_{(2,57)}=0.332, p=0.718\right)$ for the pyramidal cell layer of the CA2 region (dorsal: $M=1, S D=0.12$; intermediate: $M=0.97, S D=0.16$; ventral: $M=1.01, S D=0.13$; Figure 5B). However, the ventral Stratum radiatum $(M=1.21, S D=0.2)$ exhibited significantly higher D2R levels $\left(F_{(2,57)}=7.259, p<0.01\right)$ as opposed to the dorsal $(M=1, S D=0.15)$ and intermediate parts $(M=1.04, S D=0.19$; Figure $5 \mathrm{C})$. In case of the Stratum lacunosum-moleculare of the CA2 region, the ventral portion of the hippocampus $(M=1.22, S D=0.19)$ has also exhibited significantly higher expression of D2R $\left(F_{(2,57)}=8.427\right.$, $p<0.001)$ compared to the dorsal $(M=1, S D=0.14)$ and intermediate parts $(M=1.05, S D=0.2$; Figure 5D).

\section{D2R Expression Is Higher in the Ventral CA1 Region}

D2R expression levels were uniformly higher across the non-somatic sublayers of the ventral CA1 region compared to the dorsal CA1 (Figure 6). Thus, expression was found to be

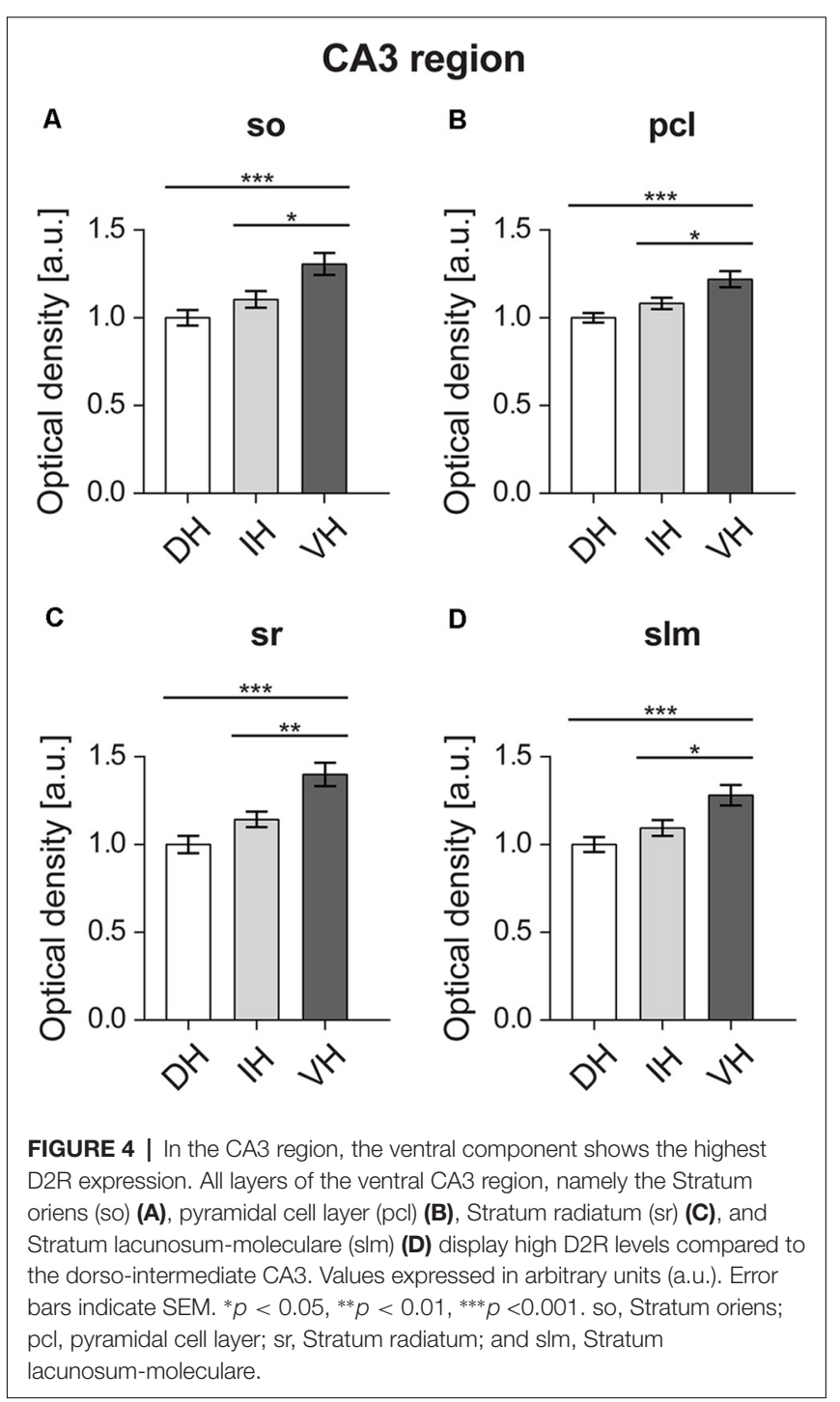

the highest in the ventral Stratum oriens $(M=1.14, S D=0.19)$ of the CA1 region $\left(F_{(2,57)}=3.492, p<0.05\right)$ as opposed to the dorsal part $(M=1, S D=0.14)$, while no differences were observed with the intermediate part $(M=1.02, S D=0.2$; Figure 6A). In case of the Stratum radiatum, the ventral hippocampus $(M=1.17, S D=0.19)$ showed significantly higher D2R levels $\left(F_{(2,57)}=4.561, p<0.05\right)$ compared to the dorsal part $(M=1$, $S D=0.17)$. The intermediate $\operatorname{sr}(M=1.04, S D=0.21)$ was not significantly different from its counterparts (Figure 6C). The Stratum lacunosum-moleculare followed a similar pattern $\left(F_{(2,57)}=9.07, p<0.001\right)$ and exhibited higher receptor levels in the ventral portion $(M=1.28, S D=0.2)$ as opposed to the dorsal $(M=1, S D=0.19)$ and intermediate ones $(M=1.1$, $S D=0.23$; Figure 6D).

Receptor expression was of similar level $\left(F_{(2,57)}=2.018\right.$, $p=0.142)$ in the dorsal $(M=1, S D=0.16)$, intermediate $(M=1.02, S D=0.17)$ and ventral pyramidal cell layers of the CA1 region $(M=1.1, S D=0.19$; Figure 6B $)$. 


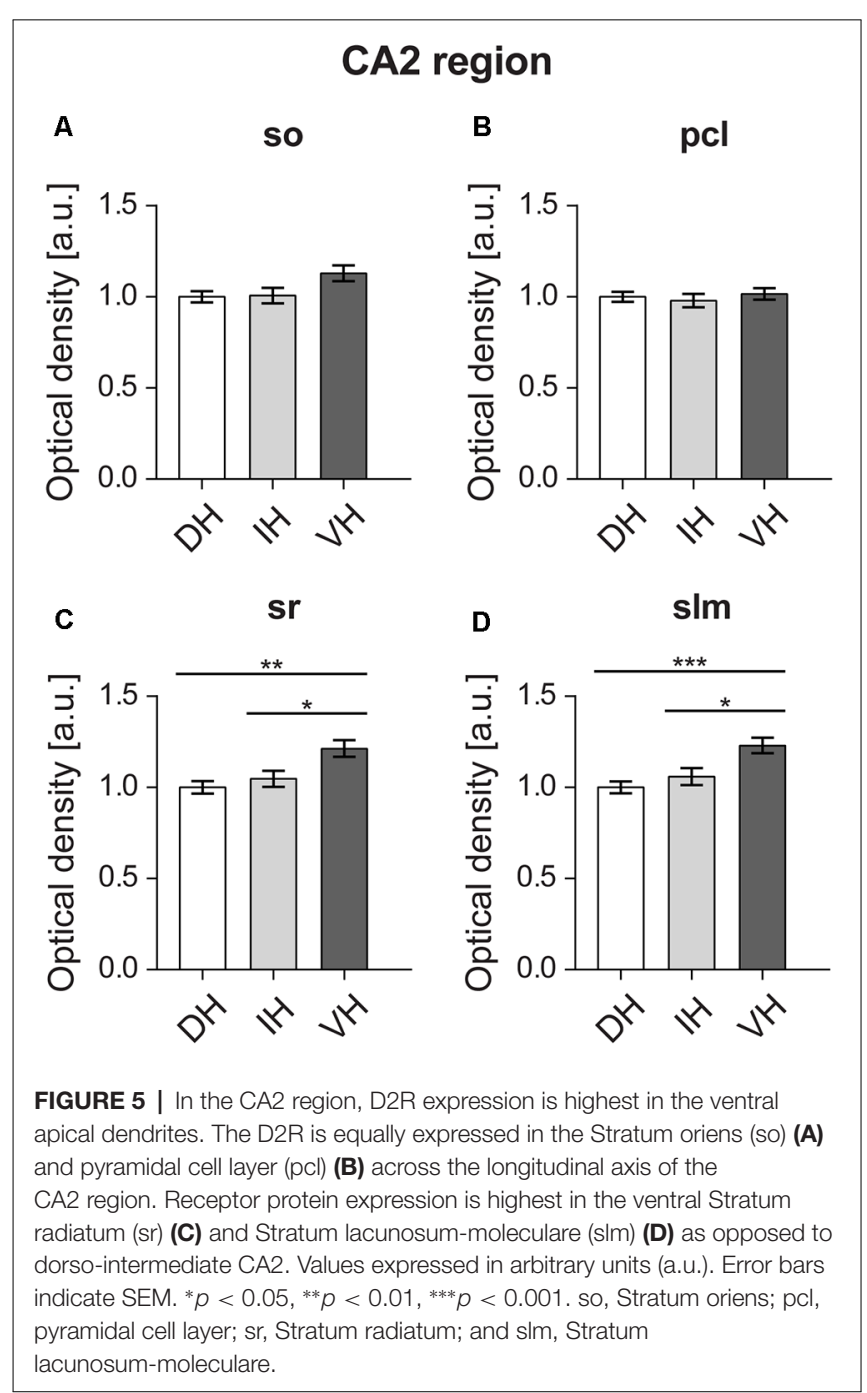

\section{DISCUSSION}

In this study, we report that the D2R expression differs across the dorsal, intermediate and ventral hippocampus of rat. Specifically, we demonstrate that the total D2R levels are the highest in all layers of the ventral DG and CA3 regions, as well as in the dendritic layers of the ventral CA2 and CA1 regions. The dorsal hippocampus shows the overall lowest D2R content, while the intermediate part shows levels that are either in-between the differing levels of the dorsal and ventral poles, or alternatively are equivalent to levels detected in one of the poles. Testing of antibody specificity revealed protein labeling at $55 \mathrm{kDa}$. This corresponds to the $\mathrm{D} 2 \mathrm{~L}$ dopamine receptor that is postsynaptic (Lindgren et al., 2003; Gemechu et al., 2018).

Importantly, our study is the first to provide a more complete picture of D2R expression across the hippocampal dorso-ventral axis, as the majority of already published studies focused on brain regions other than the hippocampus (Vincent et al., 1993; Sesack et al., 1994; Yung et al., 1995; Lazarov and Pilgrim, 1997; Jung and Bolam, 2000) or on animal species other than the rat (Khan et al., 1998; Gangarossa et al., 2012; Puighermanal

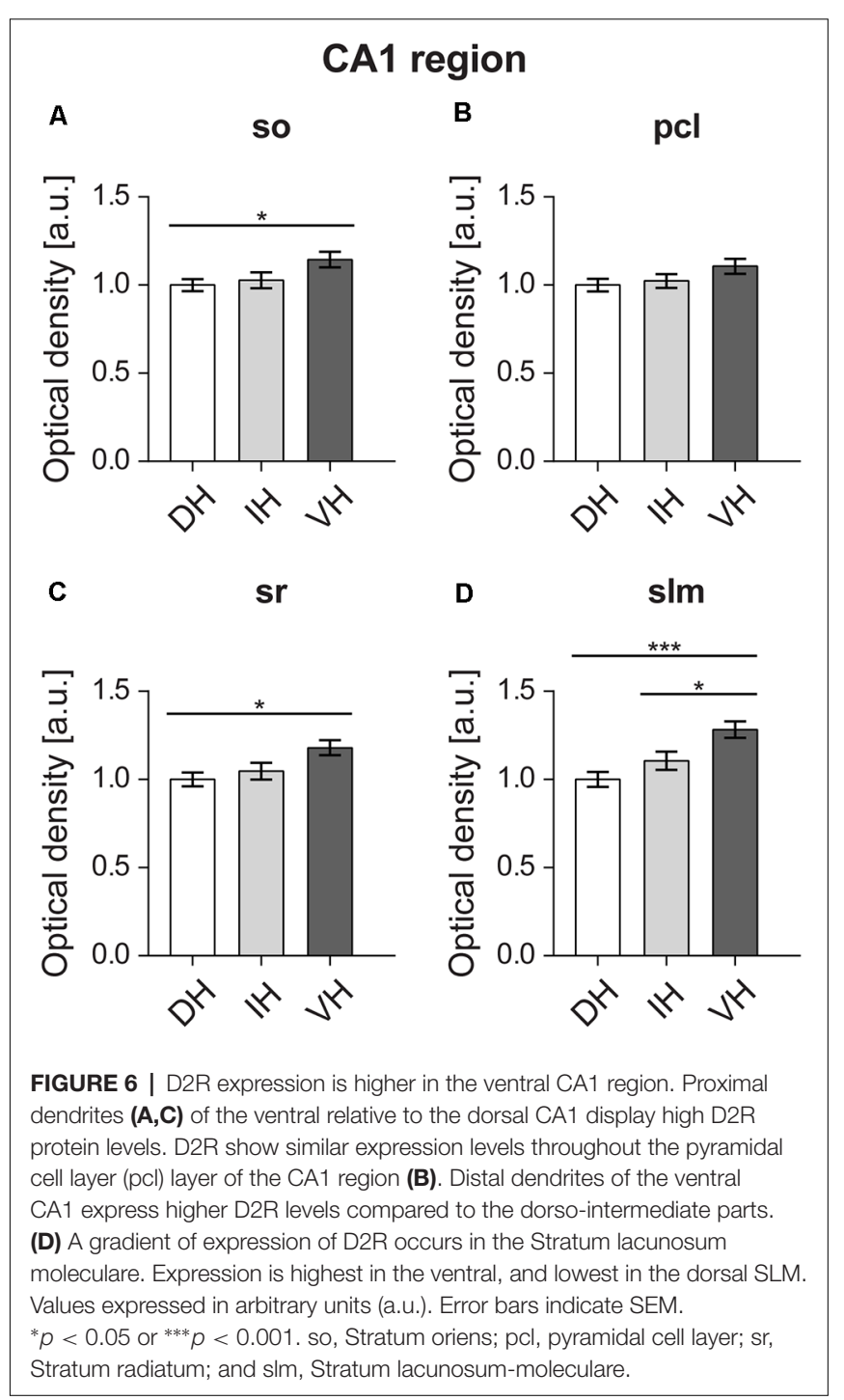

et al., 2015; Wei et al., 2017). Only very few studies report on aspects of the $\mathrm{D} 2 \mathrm{R}$ expression in the rat hippocampus. Among them, an immunocytochemical study by Levey et al. (1993) described relatively low D2R immunoreactivity in the hippocampus on sagittal sections from albino rat brains. An earlier autoradiographic study reported the presence of D2R high-density binding sites in the Stratum lacunosum-moleculare of the dorsal CA1 and lower densities in the rest of the rat hippocampus (Charuchinda et al., 1987). The most recent work by Yu et al. (2019) demonstrated cellular expression patterns of $\mathrm{D} 2 \mathrm{R}$ in transgenic rat forebrain. They studied $\mathrm{D} 2 \mathrm{R}$ positive cells across the transverse axis of only the dorsal hippocampus and reported on $\mathrm{D} 2 \mathrm{R}$ expression in the pyramidal cell layer and Stratum radiatum of the CA1-3 regions and the DG, as well as in axon terminals innervating the Stratum lacunosummoleculare of the CA1 region. With regard to the dorso-ventral distribution of the D2R only one study has addressed this to date. Using a radioligand binding assay, Bruinink and Bischoff, 1993, demonstrated a bimodal distribution from the dorsal to 
the ventral hippocampus that comprised a high D2R density in one portion of the dorsal part and in the entire ventral part. The results of our current study are in line with this report. We show here that the ventral hippocampus has the highest expression density of D2R. The discrepancy between a bimodal distribution in the aforementioned study and a lack thereof in our case, is probably because in our examination of the D2R expression we used sections from the dorsal part that are very close to the tip of the hippocampus, while in the Bruinink and Bischoff study the dorsal hippocampus was separated into three subdivisions, whereupon the one closest to the intermediate hippocampus showed the high receptor density. Moreover, this study showed that the proportion of the $\mathrm{D} 2 \mathrm{R}$ in the high affinity state is higher in the dorsal hippocampus as opposed to the ventral one (Bruinink and Bischoff, 1993). This may have masked differences in receptor distribution, especially considering that the amount of dopaminergic projections reaching the hippocampus is more dense in the ventral portion (Verney et al., 1985). Interestingly, dopamine D1 receptors show a similar pattern of expression along the dorsoventral axis (Dubovyk and Manahan-Vaughan, 2018), with higher levels being apparent in the ventral and intermediate CA1 region compared to the dorsal part. Here, in particular, expression is higher in the ventral and intermediate Stratum lacunosum-moleculare and Stratum radiatum of the CA1 region (Dubovyk and Manahan-Vaughan, 2018).

Studies that scrutinized the binding affinity of D1-like and D2-like receptors (Edelmann and Lessmann, 2018) showed that, at low concentrations, dopamine activates presynaptic D2R leading to a reduction of excitatory responses in the hippocampal CA1 neurons. These findings suggest that during the tonic firing of dopaminergic neurons projecting to the hippocampus, the D2R become activated first, adding to a generalized inhibition of neuronal excitatory postsynaptic currents. This interpretation is consistent with findings, in behaving rats, that intracerebral application of a D2R agonist reduces basal synaptic transmission in the hippocampus (Manahan-Vaughan and Kulla, 2003). These low concentrations of D2R agonist also inhibit vulnerable forms of LTP (Manahan-Vaughan and Kulla, 2003). This process may serve to enhance signal-to-noise ratios and prevent the long-term storage of less salient information.

At higher concentrations, dopamine begins to activate other D2-like receptors followed by D1-like receptors (Gribkoff and Ashe, 1984; Hsu, 1996; van Wieringen et al., 2013). In line with this, high D2R agonist concentrations increase the spontaneous firing rate of dorsal CA1 pyramidal neurons in rat slices (Smiaowski and Bijak, 1987), as well as in the dorsal DG granule cells of freely moving rats (Yanagihashi et al., 1991). Given our finding of an overall dorso-ventral gradient in the D2R expression, it is tempting to assume that the ventral hippocampus may be under a stronger inhibitory control upon tonic dopamine release, but may have an increased neuronal excitability when phasic elevations of dopamine levels occur. This may explain why neuroleptics that antagonize dopamine D2R ameliorate the symptoms of acute, or positive, symptoms of psychosis (Giannini et al., 2000; Dold et al., 2015): by antagonizing the receptor, the balance of activity is restored to one that mediates neuronal inhibition, as opposed to excitation. Our study suggests that these effects may be mediated predominantly by the ventral hippocampus, an interpretation that is supported by studies that suggest that the ventral (and not the dorsal) hippocampus engages predominantly in information processing related to affective state (Fanselow and Dong, 2010).

The involvement of $\mathrm{D} 2 \mathrm{R}$ signaling in the modulation of hippocampal synaptic plasticity has been described by several studies. For example, pharmacological blockade of D2R, using a ligand concentration that does not affect basal synaptic transmission, prevents a weak form of long-term potentiation (LTP) in the dorsal DG in vivo (Manahan-Vaughan and Kulla, 2003). This study also reported an involvement of the D2R in the regulation of depotentiation, which involves a reversal of recently induced LTP (Manahan-Vaughan and Kulla, 2003). With regard to the CA1 region of hippocampal slices, antagonism of D2R inhibits LTP maintenance but has no effect on the initiation phase (Frey et al., 1989, 1990). Activation of D2-like receptors results in inhibition of long-term depression (LTD) in the CA1 region in vitro (Chen et al., 1996). While all of the reported studies on synaptic plasticity have been performed on the dorsal part of the rat hippocampus, only one such study was performed on the ventral part, in this case, of the mouse hippocampus (Rocchetti et al., 2015). Here, the authors reported that both LTP and LTD were severely impaired in the ventral CA1 of hippocampal slices from D2R knockout mice, as well as following the pharmacological blockade of the D2R in naive mice. Moreover, they showed that specific deletion of presynaptic D2R leads to deficits in LTD, but not in LTP. All of these studies show that $\mathrm{D} 2 \mathrm{R}$ plays a significant role in the expression of hippocampal synaptic plasticity at both, dorsal and ventral hippocampal parts and, at least, in the DG and CA1 regions.

Mechanistically, the D2R-dependent modulation of synaptic plasticity may occur through GABAergic interneurons, as receptor activation was shown to reduce GABA synthesis in the hippocampus (Steulet et al., 1990), thus allowing for LTP to occur (Wigström and Gustafsson, 1983). However, higher D2R expression in the ventral hippocampus does not seem to be able to fully compensate for differences in LTP between the dorsal and ventral hippocampal parts, as LTP is known to be of lower magnitude in the ventral CA1 compared to its dorsal counterpart (Dubovyk and Manahan-Vaughan, 2018). This difference relates to expression levels of subunits of the NMDA receptor (Dubovyk and Manahan-Vaughan, 2018), but may also relate to differences in $\mathrm{D} 2 \mathrm{R}$ expression and/or to the expression of other neurotransmitter receptors. Further studies are required to access the precise contribution of $\mathrm{D} 2 \mathrm{R}$ to synaptic plasticity in other CA regions as well as in the intermediate hippocampus.

Functionally, the D2R has been implicated in hippocampusdependent learning and memory: systemic application of receptor blockers triggers an array of learning and memory deficits (Gasbarri et al., 1993; Sigala et al., 1997; Stuchlik et al., 2007; Rocchetti et al., 2015). Similarly, D2R knockout mice have impaired both, short-term and long-term spatial memory as well as recognition memory (Rocchetti et al., 2015). Interestingly, a direct infusion of a D2R antagonist into the ventral hippocampus of wildtype mice reproduced learning 
deficits observed in the D2R knockout mice (Rocchetti et al., 2015). The same was found for the rat upon $D 2 R$ blockade in the ventral hippocampus (Wilkerson and Levin, 1999; Umegaki et al., 2001), suggesting that the systemic effect on spatial learning and memory may, in fact, be mediated by the ventrally expressed D2R. Interestingly, systemic injection of D2R agonist (Imperato et al., 1993, 1994), as well as focal injection into the ventral hippocampus, dose-dependently stimulates acetylcholine release (Umegaki et al., 2001). However, injection of the D2R agonist into the dorsal hippocampus had no such effect on hippocampal acetylcholine release (Day and Fibiger, 1994). Therefore, the involvement of the D2R in memory performance in the ventral hippocampus may happen through the regulation of acetylcholine release.

Accurate spatial navigation is thought to be mediated by place-cell representation of spatial context (Eichenbaum et al., 1999) that is known to differ in the dorsal and ventral hippocampus (Strange et al., 2014). Here, the density of place cells, size of the place fields and their precision are known to gradually change from pole to pole (Jung et al., 1994). Importantly, in D2R knockout mice, the number of place cells is significantly decreased and is accompanied by changes in basic firing properties (intra-field firing rate, spatial tuning and spatial coherence) and reduced stability of place fields (Nguyen et al., 2014). Therefore, the difference in $D 2 R$ expression between the dorsal and ventral hippocampus that was found in the current work may also account, in part, for dorso-ventral differences in place cells and place fields properties, whereupon the dorsal part encodes high-resolution spatial information for a small environment, while the ventral part processes low-resolution information for a larger environment.

It has been proposed that the hippocampal dorso-ventral axis is functionally segregated on a cognitive level. Whereas the dorsal part is predominantly engaged in visuo-spatial information processing, the ventral part is involved in emotional, motivational and affective responses (Fanselow and Dong, 2010; Strange et al., 2014). The intermediate part may integrate information from both poles (Bast et al., 2009; Fanselow and Dong, 2010; Strange et al., 2014). Interestingly, the ventrointermediate hippocampal subfields receive a more intense afferent projection form the VTA than does the dorsal subfield (Gasbarri et al., 1994). The higher expression levels of D2R receptors as reported in the present study, along with higher levels of D1DR as reported previously (Dubovyk and ManahanVaughan, 2018), suggest that the ventral hippocampus is subjected to quite potent control by the VTA. This indicates

\section{REFERENCES}

Bast, T., Wilson, I. A., Witter, M. P., and Morris, R. G. M. (2009). From rapid place learning to behavioral performance: a key role for the intermediate hippocampus. PLoS Biol. 7:e1000089. doi: 10.1371/journal.pbio.1000089

Beaulieu, J. M., and Gainetdinov, R. R. (2011). The physiology, signaling, and pharmacology of dopamine receptors. Pharmacol. Rev. 63, 182-217. doi: 10.1124/pr.110.002642

Bruinink, A., and Bischoff, S. (1993). Dopamine $\mathrm{D}_{2}$ receptors are unevenly distributed in the rat hippocampus and are modulated differently than in turn, that the ventral part of the hippocampus should be subjected to much closer scrutiny in terms of obtaining an understanding of how the dopaminergic system engages with the hippocampus, and enables hippocampal information encoding and hippocampus-dependent non-spatial behavior.

\section{CONCLUSION}

Taken together, our study demonstrates that the overall expression of dopaminergic D2R is strikingly different between the ventral pole of the hippocampus and its dorso-intermediate two-thirds of the dorso-ventral axis. In all hippocampal sublayers studied, expression levels were always highest in the ventral compared to the dorsal pole. This difference is likely to contribute to known dorso-ventral differences in synaptic plasticity (Dubovyk and Manahan-Vaughan, 2018) as well as to state-dependent learning and memory.

\section{DATA AVAILABILITY STATEMENT}

The data that support the findings of this study are available from the corresponding author upon reasonable request.

\section{ETHICS STATEMENT}

The animal study was reviewed and approved by Landesamt für Arbeitsschutz, Naturschutz, Umweltschutz und Verbraucherschutz, NRW, Germany.

\section{AUTHOR CONTRIBUTIONS}

The study was designed by DM-V and VD. Experiments were conducted by VD and analyzed by both authors. VD and DM-V wrote the article.

\section{FUNDING}

This work was supported by a German Research Foundation (Deutsche Forschungsgemeinschaft, DFG) grant to DM-V (SFB 1280/A04, project number: 316803389).

\section{ACKNOWLEDGMENTS}

We gratefully thank Ute Neubacher and Beate Krenzek for technical assistance and Nadine Kollosch for animal care.

in striatum. Eur. J. Pharmacol. 245, 157-164. doi: 10.1016/0922-4106(93) 90123-q

Charuchinda, C., Supavilai, P., Karobath, M., and Palacios, J. M. (1987). Dopamine D2 receptors in the rat brain: autoradiographic visualization using a high-affinity selective agonist ligand. J. Neurosci. 7, 1352-1360. doi: 10.1523/JNEUROSCI.07-05-01352.1987

Chaudhuri, K. R., and Schapira, A. H. (2009). Non-motor symptoms of Parkinson's disease: dopaminergic pathophysiology and treatment. Lancet Neurol. 8, 464-474. doi: 10.1016/S1474-4422(09) 70068-7 
Chen, Z., Ito, K., Fujii, S., Miura, M., Furuse, H., Sasaki, H., et al. (1996). Roles of dopamine receptors in long-term depression: enhancement via D1 receptors and inhibition via $\mathrm{D} 2$ receptors. Receptors Channels 4, 1-8.

Citri, A., and Malenka, R. C. (2008). Synaptic plasticity: multiple forms, functions, and mechanisms. Neuropsychopharmacology 33, 18-41. doi: 10.1038/sj.npp. 1301559

Day, J. C., and Fibiger, H. C. (1994). Dopaminergic regulation of septohippocampal cholinergic neurons. J. Neurochem. 63, 2086-2092. doi: 10.1046/j.1471-4159.1994.63062086.x

De Mei, C., Ramos, M., Iitaka, C., and Borrelli, E. (2009). Getting specialized: presynaptic and postsynaptic dopamine D2 receptors. Curr. Opin. Pharmacol. 9, 53-58. doi: 10.1016/j.coph.2008.12.002

Dold, M., Samara, M. T., Li, C., Tardy, M., and Leucht, S. (2015). Haloperidol versus first-generation antipsychotics for the treatment of schizophrenia and other psychotic disorders. Cochrane Database Syst. Rev. 1:CD009831. doi: 10.1002/14651858.cd009831.pub2

Dubovyk, V., and Manahan-Vaughan, D. (2018). Less means more: the magnitude of synaptic plasticity along the hippocampal dorso-ventral axis is inversely related to the expression levels of plasticity-related neurotransmitter receptors. Hippocampus 28, 136-150. doi: 10.1002/hipo.22816

Duszkiewicz, A. J., McNamara, C. G., Takeuchi, T., and Genzel, L. (2019). Novelty and dopaminergic modulation of memory persistence: a tale of two systems. Trends Neurosci. 42, 102-114. doi: 10.1016/j.tins.2018.10.002

Edelmann, E., and Lessmann, V. (2018). Dopaminergic innervation and modulation of hippocampal networks. Cell Tissue Res. 373, 711-727. doi: 10.1007/s00441-018-2800-7

Eichenbaum, H., Dudchenko, P., Wood, E., Shapiro, M., and Tanila, H. (1999). The hippocampus, memory, and place cells: it is spatial memory or a memory space? Neuron 23, 209-226. doi: 10.1016/s0896-6273(00)80773-4

Etter, G., and Krezel, W. (2014). Dopamine D2 receptor controls hilar mossy cells excitability. Hippocampus 24, 725-732. doi: 10.1002/hipo.22280

Fanselow, M. S., and Dong, H. W. (2010). Are the dorsal and ventral hippocampus functionally distinct structures? Neuron 65, 7-19. doi: 10.1016/j.neuron.2009. 11.031

Frey, U., Hartmann, S., and Matthies, H. (1989). Domperidone, an inhibitor of the D2-receptor, blocks a late phase of an electrically induced long-term potentiation in the CA1-region in rats. Biomed. Biochim. Acta 48, $473-476$.

Frey, U., Schroeder, H., and Matthies, H. (1990). Dopaminergic antagonists prevent long-term maintenance of posttetanic LTP in the CA1 region of rat hippocampal slices. Brain Res. 522, 69-75. doi: 10.1016/0006-8993(90)91578-5

Gangarossa, G., Longueville, S., De Bundel, D., Perroy, J., Hervé, D., Girault, J. A., et al. (2012). Characterization of dopamine D1 and D2 receptorexpressing neurons in the mouse hippocampus. Hippocampus 22, 2199-2207. doi: 10.1002/hipo.22044

Gasbarri, A., Introini-Collison, I. B., Packard, M. G., Pacitti, C., and McGaugh, J. L. (1993). Interaction of cholinergic-dopaminergic systems in the regulation of memory storage in aversively motivated learning tasks. Brain Res. 627, 72-78. doi: 10.1016/0006-8993(93)90750-h

Gasbarri, A., Sulli, A., and Packard, M. G. (1997). The dopaminergic mesencephalic projections to the hippocampal formation in the rat. Prog. Neuropsychopharmacol. Biol. Psychiatry 21, 1-22. doi: 10.1016/s02785846(96)00157-1

Gasbarri, A., Packard, M. G., Campana, E., and Pacitti, C. (1994). Anterograde and retrograde tracing of projections from the ventral tegmental area to the hippocampal formation in the rat. Brain Res. Bull. 33, 445-452.

Gemechu, J. M., Sharma, A., Yu, D., Xie, Y., Merkel, O. M., and Moszczynska, A. (2018). Characterization of dopaminergic system in the striatum of young adult Park2-/- knockout rats. Sci Rep. 8:1517. doi: 10.1038/s41598-017-18526-0

Giannini, A. J., Underwood, N. A., and Condon, M. (2000). Acute ketamine intoxication treated by haloperidol. Am. J. Ther. 7, 389-391. doi: 10.1097/00045391-200007060-00008

Gingrich, J. A., and Caron, M. G. (1993). Recent advances in the molecular biology of dopamine receptors. Annu. Rev. Neurosci. 16, 299-321. doi: 10.1146/annurev.ne.16.030193.001503

Gribkoff, V., and Ashe, J. (1984). Modulation by dopamine of population responses and cell membrane properties of hippocampal CA1 neurons in vitro. Brain Res. 292, 327-338. doi: 10.1016/0006-8993(84)90768-6
Hansen, N., and Manahan-Vaughan, D. (2014). Dopamine D1/D5 receptors mediate informational saliency that promotes persistent hippocampal long-term plasticity. Cereb. Cortex 24, 845-858. doi: 10.1093/cercor/bhs362

Hansen, N., and Manahan-Vaughan, D. (2015). Hippocampal long-term potentiation that is elicited by perforant path stimulation or that occurs in conjunction with spatial learning is tightly controlled by $\beta$-adrenoreceptors and the locus coeruleus. Hippocampus 25, 1285-1298. doi: 10.1002/hipo. 22436

Hsu, K. S. (1996). Characterization of dopamine receptors mediating inhibition of excitatory synaptic transmission in the rat hippocampal slice. J. Neurophysiol. 76, 1887-1895. doi: 10.1152/jn.1996.76.3.1887

Imperato, A., Obinu, M. C., Dazzi, L., Carta, G., Mascia, M. S., Casu, M. A., et al. (1994). Co-dergocrine (Hydergine) regulates striatal and hippocampal acetylcholine release through D2 receptors. Neuroreport 5, 674-676. doi: 10.1097/00001756-199402000-00003

Imperato, A., Obinu, M. C., and Gessa, G. L. (1993). Stimulation of both $D_{1}$ and $\mathrm{D}_{2}$ receptors facilitates in vivo acetylcholine release in the hippocampus. Brain Res. 618, 341-345. doi: 10.1016/0006-8993(93)91288-4

Jung, K. K., and Bolam, J. P. (2000). Localization of dopamine D1 and D2 receptors in the rat neostriatum: synaptic interaction with glutamate- and GABA-containing axonal terminals. Synapse 38, 413-420. doi: 10.1002/10982396(20001215)38:4<413::aid-syn6>3.3.co;2-m

Jung, M. W., Wiener, S. I., and McNaughton, B. L. (1994). Comparison of spatial firing characteristics of units in dorsal and ventral hippocampus of the rat. J. Neurosci. 14, 7347-7356. doi: 10.1523/JNEUROSCI.14-12-07347.1994

Kemp, A., and Manahan-Vaughan, D. (2005). The 5-hydroxytryptamine4 receptor exhibits frequency-dependent properties in synaptic plasticity and behavioural metaplasticity in the hippocampal CA1 region in vivo. Cereb. Cortex 15, 1037-1043. doi: 10.1093/cercor/bhh204

Kempadoo, K. A., Mosharov, E. V., Choi, S. J., Sulzer, D., and Kandel, E. R. (2016). Dopamine release from the locus coeruleus to the dorsal hippocampus promotes spatial learning and memory. Proc. Natl. Acad. Sci. U S A 113, 14835-14840. doi: 10.1073/pnas.1616515114

Khan, Z. U., Mrzljak, L., Gutierrez, A., de la Calle, A., and Goldman-Rakic, P. S. (1998). Prominence of the dopamine D2 short isoform in dopaminergic pathways. Proc. Natl. Acad. Sci. U S A 95, 7731-7736. doi: 10.1073/pnas.95.13. 7731

Kreutz, C., Bartolome Rodriguez, M. M., Maiwald, T., Seidl, M., Blum, H. E., Mohr, L., et al. (2007). An error model for protein quantification. Bioinformatics 20, 2747-2753. doi: 10.1093/bioinformatics/btm397

Kulla, A., and Manahan-Vaughan, D. (2000). Dopamine D1 receptors modulate depotentiation in the dentate gyrus of freely moving rats. Cereb. Cortex 10, 614-620. doi: 10.1093/cercor/10.6.614

Lavian, H., Loewenstern, Y., Madar, R., Almog, M., Bar-Gad, I., Okun, E., et al. (2018). Dopamine receptors in the rat entopeduncu-lar nucleus. Brain Struct. Funct. 223, 2673-2684. doi: 10.1007/s00429-018-1657-6

Lazarov, N., and Pilgrim, C. (1997). Localization of $\mathrm{D}_{1}$ and $\mathrm{D}_{2}$ dopamine receptors in the rat mesencephalic trigeminal nucleus by immunocytochemistry and in situ hybridization. Neurosci. Lett. 236, 83-86. doi: 10.1016/s03043940(97)00761-1

Lemon, N., and Manahan-Vaughan, D. (2012). Dopamine D1/D5 receptors contribute to de novo hippocampal LTD mediated by novel spatial exploration or locus coeruleus activity. Cereb. Cortex 22, 2131-2138. doi: 10.1093/cercor/bhr297

Lemon, N., Aydin-Abidin, S., Funke, K., and Manahan-Vaughan, D. (2009). Locus coeruleus activation facilitates memory encoding and induces hippocampal LTD that depends on beta-adrenergic receptor activation. Cereb. Cortex 19, 2827-2837. doi: 10.1093/cercor/bhp065

Levey, A. I., Hersch, S. M., Rye, D. B., Sunahara, R. K., Niznik, H. B., Kitt, C. A., et al. (1993). Localization of D1 and D2 dopamine receptors in brain with subtype-specific antibodies. Proc. Natl. Acad. Sci. U S A 90, 8861-8865. doi: 10.1073/pnas.90.19.8861

Lindgren, N., Usiello, A., Goiny, M., Haycock, J., Erbs, E., Greengard, P., et al. (2003). Distinct roles of dopamine D2L and D2S receptor isoforms in the regulation of protein phosphorylation at presynaptic and postsynaptic sites. Proc. Natl. Acad. Sci. U S A 100, 4305-4309. doi: 10.1073/pnas.0730708100

Lisman, J. (2017). Glutamatergic synapses are structurally and biochemically complex because of multiple plasticity processes: long-term potentiation, 
long-term depression, short-term potentiation and scaling. Philos. Trans. $R$. Soc. Lond. B Biol. Sci. 372:20160260. doi: 10.1098/rstb.2016.0260

Lisman, J. E., and Otmakhova, N. A. (2001). Storage, recall, and novelty detection of sequences by the hippocampus: elaborating on the SOCRATIC model to account for normal and aberrant effects of dopamine. Hippocampus 11, 551-568. doi: 10.1002/hipo.1071

Madadi Asl, M., Vahabie, A. H., and Valizadeh, A. (2019). Dopaminergic modulation of synaptic plasticity, its role in neuropsychiatric disorders, and its computation modeling. Basic Clin. Neurosci. 10, 1-12. doi: 10.32598/bcn.9. 10.125

Manahan-Vaughan, D., and Kulla, A. (2003). Regulation of depotentiation and long-term potentiation in the dentate gyrus of freely moving rats by dopamine D2-like receptors. Cereb. Cortex 13, 123-135. doi: 10.1093/cercor/13.2.123

Nguyen, C. L., Tran, A. H., Matsumoto, J., Hori, E., Uwano, T., Ono, T., et al. (2014). Hippocampal place cell responses to distal and proximal cue manipulations in dopamine D2 receptor-knockout mice. Brain Res. 1567, 13-27. doi: 10.1016/j.brainres.2014.04.023

Paxinos, G., and Watson, C. (1982). The Rat Brain in Stereotactic Coordinates. San Diego: Academic Press.

Puighermanal, E., Biever, A., Espallergues, J., Gangarossa, G., De Bundel, D., and Valjent, E. (2015). drd2-cre:ribotag mouse line unravels the pos-sible diversity of dopamine $\mathrm{d} 2$ receptor-expressing cells of the dorsal mouse hippocampus. Hippocampus 25, 858-875. doi: 10.1002/hipo.22408

Rankin, M. L., Hazelwood, L. A., Free, R. B., Namkung, Y., Rex, E. B., Roof, R. A., et al. (2009). "Molecular pharmacology of the dopamine receptors," in Dopamine Handbook, eds L. L. Iversen, S. D. Iversen, S. B. Dunnet, and A. Bjorklund (New York, NY: Oxford University Press), 63-87.

Rocchetti, J., Isingrini, E., Dal Bo, G., Sagheby, S., Menegaux, A., Tronche, F., et al. (2015). Presynaptic D2 dopamine receptors control long-term depression expression and memory processes in the temporal hippocampus. Biol. Psychiatry 77, 513-525. doi: 10.1016/j.biopsych.2014.03.013

Santana, N., Mengod, G., and Artigas, F. (2009). Quantitative analysis of the expression of dopamine D1 and D2 receptors in pyramidal and GABAergic neurons of the rat prefrontal cortex. Cereb. Cortex 19, 849-860. doi: 10.1093/cercor/bhn134

Sesack, S. R., Aoki, C., and Pickel, V. M. (1994). Ultrastructural localization of D2 receptor-like immunoreactivity in midbrain dopamine neurons and their striatal targets. J. Neurosci. 14, 88-106. doi: 10.1523/jneurosci.14-01-00088. 1994

Sibley, D. R., and Monsma, F. J. Jr. (1992). Molecular biology of dopamine receptors. Trends Pharmacol. Sci. 13, 61-69. doi: 10.1016/0165-6147(92) 90025-2

Sigala, S., Missale, C., and Spano, P. (1997). Opposite effects of dopamine D2 and D3 receptors on learning and memory in the rat. Eur. J. Pharmacol. 336, 107-112. doi: 10.1016/s0014-2999(97)01235-1

Smiaowski, A., and Bijak, M. (1987). Excitatory and inhibitory action of dopamine on hippocampal neurons in vitro. Neuroscience 23, 95-101. doi: 10.1016/03064522(87)90274-0

Smith, C. C., and Greene, R. W. (2012). CNS dopamine transmission mediated by noradrenergic innervation. J Neurosci. 32, 6072-6080. doi: 10.1523/ JNEUROSCI.6486-11.2012

Steulet, A. F., Bernasconi, R., Leonhardt, T., Martin, P., Grünenwald, C., Bischoff, S., et al. (1990). Effects of selective dopamine D1 and D2 receptor agonists on the rate of GABA synthesis in mouse brain. Eur. J. Pharmacol. 191, 19-27. doi: 10.1016/0014-2999(90)94092-c

Strange, B. A., Witter, M. P., Lein, E. S., and Moser, E. I. (2014). Functional organization of the hippocampal longitudinal axis. Nat. Rev. Neurosci. 15, 655-669. doi: 10.1038/nrn3785

Stuchlik, A., Rehakova, L., Telensky, P., and Vales, K. (2007). Morris water maze learning in Long-Evans rats is differentially affected by blockade of D1-like and D2-like dopamine receptors. Neurosci. Lett. 422, 169-174. doi: 10.1016/j.neulet. 2007.06.012

Twarkowski, H., and Manahan-Vaughan, D. (2016). Loss of catecholaminergic neuromodulation of persistent forms of hippocampal synaptic plasticity with increasing age. Front. Synaptic Neurosci. 8:30. doi: 10.3389/fnsyn.2016.00030
Umegaki, H., Munoz, J., Meyer, R. C., Spanger, E. L., Yoshimura, J., Ikari, H., et al. (2001). Involvement of dopamine D2 receptors in complex maze learning and acetylcholine release in ventral hippocampus of rats. Neuroscience 103, 27-33. doi: 10.1016/s0306-4522(00)00542-x

Usiello, A., Baik, J. H., Rougé-Pont, F., Picetti, R., Dierich, A., LeMeur, M., et al. (2000). Distinct functions of the two isoforms of dopamine D2 receptors. Nature 408, 199-203. doi: 10.1038/35041572

Vallone, D., Picetti, R., and Borrelli, E. (2000). Structure and function of dopamine receptors. Neurosci. Biobehav. Rev. 24, 125-132. doi: 10.1016/S01497634(99)00063-9

van Wieringen, J. P., Booij, J., Shalgunov, V., Elsinga, P., and Michel, M. C. (2013). Agonist high- and low-affinity states of dopamine $\mathrm{D}_{2}$ receptors: methods of detection and clinical implications. Naunyn Schmiedebergs Arch. Pharmacol. 386, 135-154. doi: 10.1007/s00210-012-0817-0

Verney, C., Baulac, M., Berger, B., Alvarez, C., Vigny, A., and Helle, K. B. (1985). Morphological evidence for a dopaminergic terminal field in the hippocampal formation of young and adult rat. Neuroscience 14, 1039-1052. doi: 10.1016/0306-4522(85)90275-1

Vincent, S. L., Khan, Y., and Benes, F. M. (1993). Cellular distribution of dopamine D1 and D2 receptors in rat medial prefrontal cortex. J. Neurosci. 13, 2551-2564. doi: 10.1523/jneurosci.13-06-02551.1993

Volkow, N. D., Fowler, J. S., Wang, G. J., Swanson, J. M., and Telang, F. (2007). Dopamine in drug abuse and addiction: results of imaging studies and treatment implications. Arch. Neurol. 64, 1575-1579. doi: 10.1001/archneur.64. 11.1575

von der Heyde, S., Sonntag, J., Kaschek, D., Bender, C., Bues, J., and Watcher, A. (2014). RPPanalyzer toolbox: an improved R package for analysis of reverse phase protein array data. Biotechniques 57, 125-135. doi: 10.2144/000114205

Wei, X., Ma, T., Cheng, Y., Huang, C. C. Y., Wang, X., Lu, J., et al. (2017). Dopamine D1 or D2 receptor-expressing neurons in the central nervous system. Addict. Biol. 23, 569-584. doi: 10.1111/adb.12512

Wigström, H., and Gustafsson, B. (1983). Facilitated induction of hippocampal long-lasting potentiation during blockade of inhibition. Nature 301, 603-604. doi: $10.1038 / 301603 \mathrm{a} 0$

Wilkerson, A., and Levin, E. D. (1999). Ventral hippocampal dopamine D1 and D2 systems and spatial working memory in rats. Neuroscience $89,743-749$. doi: 10.1016/s0306-4522(98)00346-7

Wong, D. F., Wagner, H. N., Tune, L. E., Dannals, R. F., Pearlson, G. D., Links, J. M., et al. (1986). Positron emission tomography reveals elevated D2 dopamine-receptors in drug-naive schizophrenics. Science 234, 1558-1563. doi: $10.1126 /$ science. 2878495

Yanagihashi, R., Yamanouchi, K., and Ishikawa, T. (1991). The effects of apomorphine on the hippocampal field potential in freely moving rats: pharmacological evidence of the involvement of D2 receptors. Neuropharmacology 30, 177-182. doi: 10.1016/0028-3908(91)90201-1

Yu, Q., Liu, Y. Z., Zhu, Y. B., Wang, Y. Y., Li, Q., and Yin, D. M. (2019). Genetic labeling reveals temporal and spatial expression pattern of D2 dopamine receptor in rat forebrain. Brain Struct. Funct. 224, 1035-1049. doi: 10.1007/s00429-018-01824-2

Yung, K. K., Bolam, J. P., Smith, A. D., Hersch, S. M., Ciliax, B. J., and Levey, A. I. (1995). Immunocytochemical localization of D1 and D2 dopamine receptors in the basal ganglia of the rat: light and electron microscopy. Neuroscience 65 , 709-730. doi: 10.1016/0306-4522(94)00536-e

Conflict of Interest: The authors declare that the research was conducted in the absence of any commercial or financial relationships that could be construed as a potential conflict of interest.

Copyright $\odot 2019$ Dubovyk and Manahan-Vaughan. This is an open-access article distributed under the terms of the Creative Commons Attribution License (CC BY). The use, distribution or reproduction in other forums is permitted, provided the original author(s) and the copyright owner(s) are credited and that the original publication in this journal is cited, in accordance with accepted academic practice. No use, distribution or reproduction is permitted which does not comply with these terms. 